\title{
A THEORETICAL AND EXPERIMENTAL STUDY FOR A HUMIDIFICATION - DEHUMIDIFICATION (HD) SOLAR DESALINATION UNIT
}

\author{
M.Abd ElKader, Aref., A., Gamal H. Moustafa, Yasser ElHenawy \\ Department of Mechanical Power Engineering, \\ Faculty of Engineering, Suez Canal University, Egypt
}

\begin{abstract}
A humidification-dehumidification (HD) solar desalination unit was designed. It seems to be suitable to provide drinking water for population or remote arid areas. Solar water and solar air collectors were designed to provide the hot water and air to the desalination chamber. The desalination chamber was divided into humidifier and dehumidifier towers. The circulation of air in the two towers was maintained by the forced convection. Theoretical and experimental works were done at different environmental conditions. A mathematical model was formulated, in which the thermodynamic relations were used to study the flow, heat and mass transfer inside the humidifier and dehumidifier. Such a technique was performed in order to increase the unit performance. Heat and mass balance was done and a set of governing equations was solved using the finite difference technique. The solar intensity was measured along the working day during the summer and winter months and a comparison between the theoretical and experimental results were performed. The average accumulative productivity of the system in November, December and January was ranged between 2 to $3.5 \mathrm{~kg} / \mathrm{m}^{2}$ day while the average summer productivity was found between 6 to $8 \mathrm{~kg} / \mathrm{m}^{2}$ day in June and 7.26 to $11 \mathrm{~kg} / \mathrm{m}^{2}$ day in July and August.

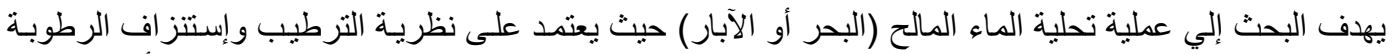

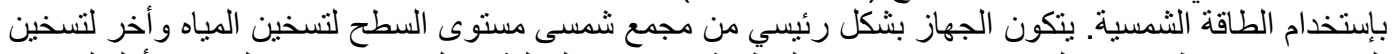

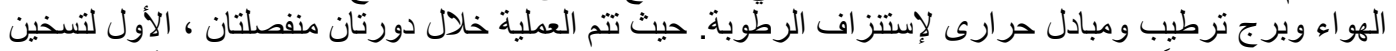

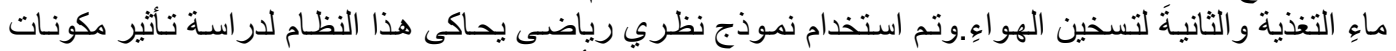

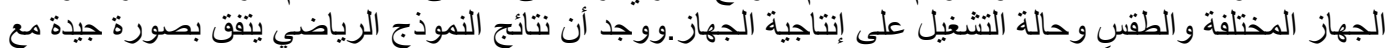

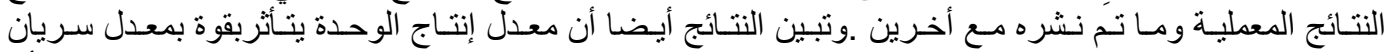

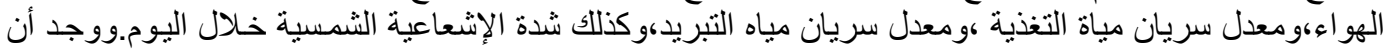

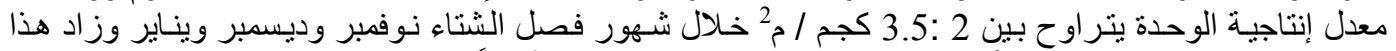

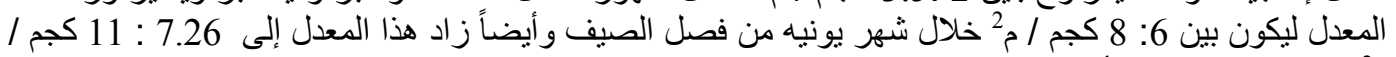

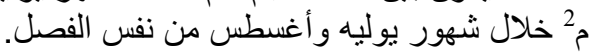

Keywords: Solar desalination, Solar collector, Humidification and Dehumidification, Solar intensity, Simulation; Finite difference, Water productivity

\section{INTRODUCTION}

Solar desalination is a suitable solution to supply remote regions in Egypt and other countries with fresh water. The standard techniques, like MultiStage Flash (MSF), Multi-Effect (ME), Vapor Compression (VC) and Reverse Osmosis (RO), are only reliable for large capacity ranges (100-50,000 $\mathrm{m}^{3} /$ day) of the fresh water production [7]. These technologies are expensive for small amounts of fresh water and also can not be used in locations where there are limited maintenance facilities. In addition, the use of conventional energy sources to drive these technologies has a negative impact on the environment. Solar desalination processes is a future promising technology, has the following advantages [8]. (i) Solar energy is environmental friendly energy source, cost-free energy, and (ii) reduced operating costs and its simple structure so that it is suitable for a few families or small groups in remote areas.

Solar desalination can either be direct or indirect [8]. The direct solar humidification dehumidification desalination process (solar still) was investigated by Nafey et al. [17-19]. The indirect solar $\mathrm{HDH}$ process has the advantage of separating the heating surface from the evaporation zone, and therefore, the heating surface is relatively protected from corrosion or scale deposits. In fact, the humidification dehumidification desalination (HDD) is more costly than the conventional basin still solar desalination process [7]. Therefore, for the simplicity of design, a modest level of manufacturing technology is needed. 
Very limited configurations of the HDD process have been developed. Abdel-Monem et al. [1] experimentally and theoretically investigated the main parameters effect on the productivity of the $\mathrm{HDH}$ process. Indoor tests with constant input energy to the system were performed. The configuration consisted of humidifier, dehumidifier and heating equipments for air and water. The effect of weather conditions was not considered, and the unsteady state performance of the system was not, therefore, examined. Ettouney [6] made design and analysis of various schemes for water desalination by humidification and dehumidification system (HDH). A theoretical investigation of a humidification and dehumidification desalination system configured by $\underline{\mathrm{a}}$ double -pass flat plate solar air heater was examined by Yamali and Solmus [21]. The effect of a cooling tower on a solar desalination system was studied by Marmouch et. al [15]. Dai, et. al [4] reported the parametric analysis to improve the performance of a solar desalination unit with a humidification and dehumidification. The performance analysis of a desalination unit of heat pump with humidification and dehumidification was studied by Gao, et. al [10]. An experimental design and computer simulation of multi-effect humidification (MEH) dehumidification solar distillation was investigated by Garg et. al [11]. Fath and Ghazy [9] studied numerically a configuration that consists of a solar air heater, humidifier and dehumidifier. The feed water was not heated, and hence, the effect of water temperature was not considered. Darwish [3] suggested a system consisting of a solar pond, a humidifying column and a dehumidifying stack. He reported that the air flow rate has a strong effect on the system productivity; however, the feed water flow rate has a weak effect on the productivity. On the other hand, Al-Hallaj and Farid [2] reported that the feed water flow rate has a strong effect on the system productivity and the effect of the air flow rate is weak. In the present article a theoretical study of humidificationdehumidification desalination unit which consists of flat plate water and air solar collectors, storage tank and dehumidifier is presented. The aim is to develop a computer program and to build an experimental apparatus that can be used to study the effect of operating and design parameters as well as weather conditions on the unit performance and fresh water productivity. A Comparison with experimental results are given.

\section{SYSTEM DESCRIPTION}

A solar desalination unit with a humidification and dehumidification cycle, which is configured mainly by a flat plate solar water collector, V-groove solar air collector, a humidifier and a condenser, is shown in Fig. 1. Seawater is heated by a solar water collector and then is sprayed by a sprinkler to form a falling film at the surface of a honeycomb wall in the humidifier. The structure sketch of the humidifier is shown in Fig.2. It consists of a porous and durable honeycomb wooden, which is characterized by a large evaporation surface per unit volume of packed material. The air is heated by a solar air collector and then is forced to pass through the humidifier where it becomes hot and humid due to the heat and mass exchange between the seawater and air. Then, the humid air is cooled by the cold seawater when passing through the condenser at which the water vapor condenses and turns into fresh water. The condenser is a helix-tube type one. The cold seawater flows in the tube channel and the fresh water is produced from the condensate on the condenser surface. The remaining seawater drawn from the humidifier is cooled and collected at the bottom basin. Some of the water is fed to the solar collector again since it is not very concentrated and is still warm. Thus, the fresh water can be continually produced. The related parameters of the unit are as follows: The fan rated power is $500 \mathrm{~W}$, the humidifier volume is $800 \times 700 \times 600 \mathrm{~mm}^{3}$, the solar water collector area is $1.5 \times 1 \mathrm{~m}^{2}$, the solar air collector area is $2 \times 1 \mathrm{~m}^{2}$, and the dehumidifier heat transfer area is $0.8^{2}$.Eeperments done the range of wind speed from $0.5: 3.5 \mathrm{~m} / \mathrm{sec}$.

Various variables characterizing the present problem were measured. The water mass flow rate and unit productivity were measured by collecting the amount of water in a graduated cylinder during a prescribed time interval. The air mass flow rate was determine by measuring the air velocity by rotating vanes anemometer ; with the range $0.2: 40 \mathrm{~m} / \mathrm{s}$ with a resolution of $0.01 \mathrm{~m} / \mathrm{s}$. The air temperature was measured by a standard $\mathrm{K}$ - type thermocouple ; with the range -50 : $1000^{\circ} \mathrm{C}$, with a resolution of 0.1 : $199.9^{\circ} \mathrm{C}$ and $1{ }^{\circ} \mathrm{C}$ above ). The Global solar radiation was measured by a silicon cell Pyranometer .accuracy with an of $+/-5 \%$. The relative humidity at the inlet and outlet of each component were measured by hygrometer; with the range $5: 95 \% \mathrm{RH}$ and resolution of $0.2 \%$ ).

\section{MATHEMATICAL MODEL}

A mathematical model of the unit is presented, in which the thermodynamic relations were used to study the flow, heat and mass transfer inside the humidifier, dehumidifier, and water and air solar collectors. A set of governing one dimensional equations has been given and solved using a finite difference technique. A computer program is developed to evaluate the mathematical model. The following assumptions are considered: (i) the feed water, cooling water and feed air are constant flow rate along the day. (ii) Thermal losses to the ambient are neglected. (iii) The energy stored in the collectors is neglected. 


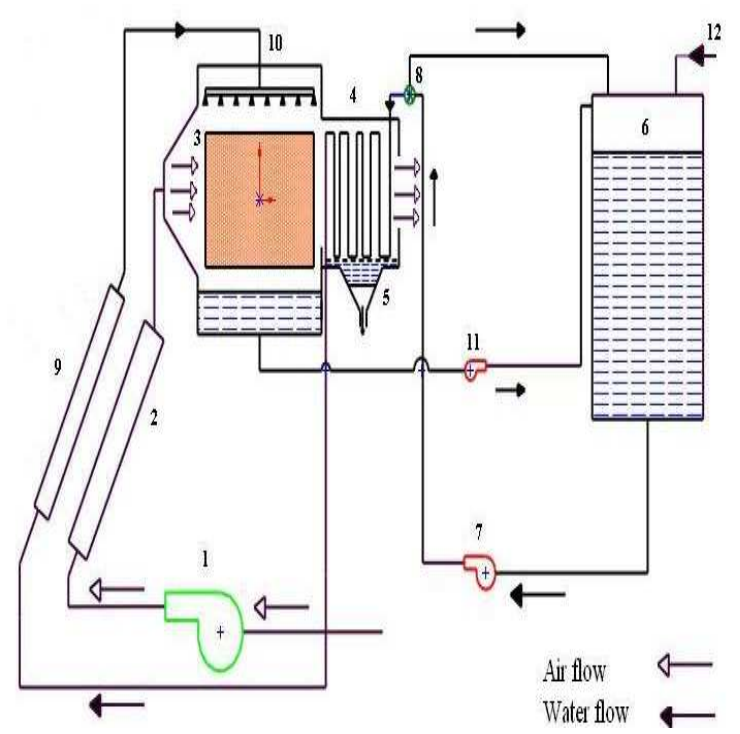

Fig.1 A Schematic diagram of desalination system.

1. Blower, 2. solar air collector, 3. humidifier, 4. dehumidifier, 5.distilled water, 6. seawater tank ,7. feed pump ,8.valve 9.solar water collector , 10. sprinkler ,11. drain pump, 12. makeup of seawater

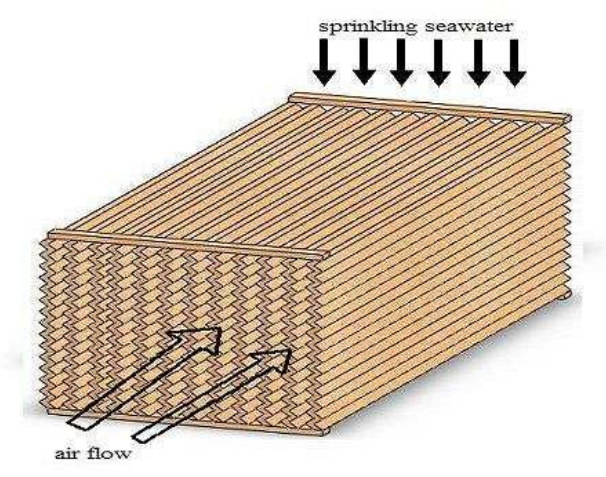

Fig. 2 A Sketch of honey-comb packing material in the humidifier

\subsection{The Flat Plate Solar Water Collector}

The thermal energy balance of the solar collector is written as follows, [16]:

$$
G_{t} \times A_{c l}=Q_{\text {loss }}+Q_{u}+Q_{s t g}
$$

Where $G_{t}$ is the total solar intensity $\left(W / \mathrm{m}^{2}\right), A_{c l}$ is the collector surface area $\left(\mathrm{m}^{2}\right), \mathrm{Q}_{\text {loss }}$ is the heat loss from the collector and $\mathrm{Q}_{\mathrm{u}}$ is the useful heat transferred from the absorber to water. $\mathrm{Q}_{\mathrm{stg}}$ is the energy stored in the collector. The heat loss is expressed by, [12]:

$$
Q_{\text {loss }}=A_{c l} U_{L}\left(T_{p}-T_{a}\right)
$$

Where $T_{p}$ is the average flat plate temperature $(K)$ through the collector and $\mathrm{T}_{\mathrm{a}}$ is the ambient temperature $(\mathrm{K})$. The overall heat transfer coefficient of the collector $\mathrm{U}_{\mathrm{L}}\left(\mathrm{W} / \mathrm{m}^{2}\right)$ is the summation of three values of heat transfer coefficients, at the top $\mathrm{U}_{t}$, at the bottom $\mathrm{U}_{\mathrm{b}}$, and at side walls $\mathrm{U}_{\mathrm{si}},[12]$.

$$
U_{L}=U_{t}+U_{b}+U_{s i}
$$

where

$$
\begin{aligned}
U_{b} & =\frac{1}{\left(\frac{\delta_{i, b}}{K_{i}}+\frac{\delta_{b, b}}{K_{b}}\right)} \cdot \frac{A_{b}}{A_{c l}} \\
U_{s i} & =\frac{1}{\left(\frac{\delta_{i, s}}{K_{i}}+\frac{\delta_{b, s}}{K_{b}}\right)} \cdot \frac{A_{s}}{A_{c l}}
\end{aligned}
$$

where $A_{s}$ and $A_{b}$ are side and bottom collector areas $\left(\mathrm{m}^{2}\right)$. The top heat transfer coefficient $U_{t}$ is calculated from an empirical equation suggested by [12]:

$$
\begin{aligned}
& U_{t}=\left\lfloor 1-(\zeta-45)\left(0.00259-0.00144 \varepsilon_{p}\right)\right\rfloor \\
& \left\{\frac{1}{N /\left[\left(344 / T_{p}\right)\left\{\left(T_{p}-T_{a}\right) /(N+f)\right\}^{0.31}\right]+1 / h_{\text {win }}}\right. \\
& \left.\quad+\frac{\sigma\left(T_{p}^{4}-T_{a}^{4}\right) /\left(T_{p}-T_{a}\right)}{\left[\varepsilon_{p}+0.0425 N\left(1-\varepsilon_{p}\right)\right]^{-1}+\left[(2 N+f-1) / \varepsilon_{g}\right]-N}\right\}
\end{aligned}
$$

where $\zeta$ is the collector tilt angle, $\mathrm{N}$ is the number of glass plate, $\varepsilon_{\mathrm{g}}$ is the emittance of glass, $\varepsilon_{\mathrm{p}}$ the emittance of absorber plate, $T_{p}$ is the average plate temperature and $\mathrm{T}_{\mathrm{a}}$ is the ambient temperature. $\sigma$ is the Boltzmann constant. The term $f$ is given as:

$$
f=\left(1-0.04 h_{\text {win }}+5 \times 10^{-4} h_{\text {win }}^{2}\right)(1+0.058 N)
$$

where $h_{\text {win }}$ is the wind heat transfer coefficient and is given by, $h_{\text {win }}=5.7+3.5 C_{\text {win }}$ where, $\mathrm{C}_{\text {win }}$ (m $/ \mathrm{sec})$ is the wind speed. The collector efficiency factor $\mathrm{F}_{\mathrm{cl}}$ is estimated by,

$$
F_{c l}=\frac{1}{S U_{L}\left[\frac{1}{U_{L}\left[D_{o}+\left(S-D_{o}\right) \eta_{f}\right]}+\frac{1}{C_{\text {bond }}}+\frac{1}{\pi D_{i} h_{t f}}\right]}
$$

where $S$ is the tube spacing $(m), D_{i}$ and $D_{o}$ are the inner and outer diameters of the collector tubes $(\mathrm{m})$. The collector fin efficiency $\eta_{\mathrm{f}}$ is calculated by, [12]:

$$
\eta_{f}=\frac{\tanh \left[\sqrt{U_{L} / K_{p} \delta_{p}}\left(s-D_{o}\right) / 2\right]}{\left[\sqrt{U_{L} / K_{p} \delta_{p}}\left(s-D_{o}\right) / 2\right]}
$$

For the flow with ( $\mathrm{Re}<2300$ ), the convective heat transfer coefficient $h_{t f}$ and the Prandtl number, Pr are given by, [16]:

$$
h_{t f}=1.86 \frac{K_{f}}{D_{i}}(\operatorname{Re} \operatorname{Pr})^{1 / 3}\left(\frac{D_{i}}{L}\right)^{1 / 3}\left(\frac{\mu_{f}}{\mu_{f, t}}\right)^{0.14}
$$


The Reynolds number (Re) and Prandtl number (Pr) are given by, [12]:

$$
\operatorname{Re}=\frac{4 m A_{c l}}{\pi D_{i} N_{t} \mu_{f}} \operatorname{Pr}=\frac{\mu_{f} C_{p, f}}{K_{f}}
$$

Where $\mathrm{k}_{\mathrm{f}}(\mathrm{W} / \mathrm{m} \mathrm{k}), \mu_{\mathrm{f}}\left(\mathrm{N} \mathrm{sec} / \mathrm{m}^{2}\right)$ and $\mathrm{C}_{\mathrm{p}}(\mathrm{J} / \mathrm{kg} \mathrm{k})$ the thermal conductivity, dynamic viscosity and specific heat of the fluid are respectively. $\mathrm{L}$ is the tube length (m). The absorbed solar radiation $\left(\mathrm{q}_{\mathrm{abs}}\right)$ is determined by, [14]:

$$
q_{a b s}=G_{t}(\tau \alpha)_{a v g}
$$

Where $(\tau \alpha)$ is the average Transmittanceabsorptance of cover plate. Also the heat removal factor $\left(F_{R}\right)$ is calculated from, [12]:

$$
F_{R}=\frac{\dot{m} C_{p}}{U}\left[1-e^{-U_{L} F_{c l} / \dot{m} C_{p}}\right]
$$

where $m$ is the mass flow rate per unit area of collector $\left(\mathrm{kg} / \mathrm{s} . \mathrm{m}^{2}\right)$. The useful energy from the collector is calculated from, [12]:

$$
Q_{u}=A_{c l} F_{R}\left[q_{a b s}-U_{L}\left(T_{f, i}-T_{a}\right)\right]
$$

The average fluid temperature is thus obtained as, [12]:

$$
T_{f, a}=T_{f, i}+\frac{Q_{u}}{A_{c l} F_{R} U_{L}}\left[1-\frac{F_{R}}{F_{c l}}\right]
$$

The average plate temperature is obtained from, [12]:

$$
T_{p}=T_{f, o}+\frac{Q_{u} / N_{t}}{\left[\frac{1}{\pi h_{t f} D_{i} L}+\frac{1}{C_{\text {bond }} L}\right]^{-1}}
$$

Where $\mathrm{N}_{t}$ is the number of tubes and $\mathrm{C}_{\text {bond }}$ is the conductive resistance of the bond. The fluid temperature at the outlet from the collector is calculated from, [12]:

$$
T_{f, o}=T_{f, i}+\frac{Q_{u}}{\dot{m} C_{p}}
$$

The collector efficiency is determined by, [14]:

$$
\eta_{c}=\frac{Q_{u}}{A_{c l} G_{t}}
$$

\subsection{Humidifier Modeling}

The humidifier consists mainly of honeycomb wooden which is characterized by a large evaporation surface per unit volume of packed material. The mathematical model of the humidifier, which is established on the basis of energy and mass balances, is presented. The heat and mass transfer between the liquid film and the moist air is considered. The set of governing two dimensional equations is solved using the finite-difference method. Assumptions are taken into account are: (i) the flow of falling film is laminar and no wavy movement takes place at the liquid-gas interface. (ii) Flow rate of falling film is believed constant because the evaporation rate of water out of the liquid-gas interface is small enough. Figure 3 shows the coordination set-up. Pleased along the interface line.

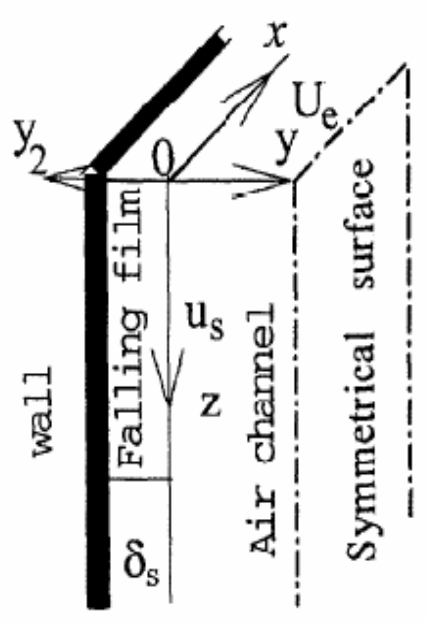

Fig.3. Coordination set-up

\subsubsection{Governing equations of falling film}

If the liquid film falls slowly and steadily just under the force of gravity, particularly in laminar flow, the mean velocity of the falling film, $u_{s}$ is given as [4]:

$u_{s}=\frac{\rho_{s} g \delta_{s}^{2}}{3 \mu_{s}}$

The thickness $\delta_{\mathrm{s}}$, Fig. 3 is given as [4]:

$\delta_{s}=\left[\frac{3 \Gamma \mu_{s}}{g \rho_{s}^{2}}\right]^{1 / 3}$

Where $\Gamma$ is the mass flow rate of saline water per unit width of the wall $(\mathrm{kg} / \mathrm{s} / \mathrm{m})$ and $\mathrm{g}$ is the acceleration of gravity, $\mathrm{m} / \mathrm{s}^{2}$. The energy balance for the falling film is 
$u_{s} \frac{\partial \mathrm{T}_{s}}{\partial z}=\alpha_{s} \frac{\partial^{2} \mathrm{~T}_{s}}{\partial y_{2}^{2}}$

\subsubsection{Governing equations of moist air}

The governing equations, including mass, momentum, and energy conservations are listed as follows [4]:

$\frac{\partial u}{\partial x}+\frac{\partial v}{\partial y}=0$

$u \frac{\partial u}{\partial x}+v \frac{\partial u}{\partial y}=\gamma_{a} \frac{\partial^{2} u}{\partial y^{2}}-\frac{1}{\rho_{a}} \frac{\partial p}{\partial x}$

$u \frac{\partial \mathrm{T}}{\partial x}+v \frac{\partial \mathrm{T}}{\partial y}=\alpha_{a} \frac{\partial^{2} \mathrm{~T}}{\partial y^{2}}$

Boundary conditions:

At $y=\frac{d}{2}-\delta_{s}, u=u_{e}, \frac{\partial u}{\partial y}=0, \mathrm{~T}=\mathrm{T}_{e}$

where $u_{e}(\mathrm{~m} / \mathrm{sec})$ and $T_{e}(K)$ are the velocity and temperature of incoming air.

- $\quad$ At the water - air interface:

$u=0, \mathrm{~T}=\mathrm{T}_{n}$, and $\mathrm{T}_{s}=\mathrm{T}_{n}$,

$\left.\alpha_{a} \frac{\partial \mathrm{T}}{\partial y}\right|_{y=0}=-\left.\alpha_{s} \frac{\partial \mathrm{T}_{s}}{\partial y_{2}}\right|_{y_{2}=0}+\frac{\lambda W_{j}}{\rho_{s} C_{p s}}$

Where $T_{n}$ is the temperature at interface, $T_{s}$ is the temperature of saline water, $\mathrm{W}_{\mathrm{j}}$ is the evaporation rate of water, and $\lambda$ is the latent heat of water. Solving the set flow equations (21-23) with boundary conditions, the distribution of the flow velocity and temperature inside the humidifier were obtained. To simplify the above solution, auxiliary equations are needed.

\section{Auxiliary equations}

The evaporation rate at the water surface estimated from, [13]:

$$
W j=\varepsilon_{1}\left(P_{s}-P_{v}\right)\left\{\frac{M}{2 \pi R T_{n}}\right\}^{1 / 2}
$$

Here $\mathrm{M}$ is the molecular weight of water and $\mathrm{R}$ is the universal gas constant $(8.314 \mathrm{~kJ} / \mathrm{kmol} \mathrm{k}) . \varepsilon_{1}$ is the Knudsen coefficient of evaporation. It is calculated from: $\varepsilon_{1}=(2 \varepsilon) /(2-\varepsilon)$. The coefficient of evaporation, $\varepsilon$ is calculated from:

$\varepsilon=h *\left[\frac{2 \pi R T_{s}}{M}\right]^{1 / 2}\left[\frac{T_{n}}{\rho_{v} \lambda^{2}}\right]$
The coefficient of heat transfer $\mathrm{h}\left(\mathrm{W} / \mathrm{m}^{2} \mathrm{~K}\right)$ is given by, [14]:

$h=\xi V^{\beta} \quad \mathrm{W} / \mathrm{m}^{2}{ }^{\circ} \mathrm{C}$

The terms $\xi$ and $\beta$ are a function of the plate spacing. For a $6.7 \mathrm{~mm}$ plate spacing the values of $\xi$ and $\beta$ are 54 and 0.7 respectively. As the plate spacing increases to $13.4 \mathrm{~mm}$, the values of $\xi$ and $\beta$ are changed to be 49 and 0.6 .

Taking the phenomenon of evaporation into account, introduced the concept of the wet bulb coefficient of heat transfer $\left(\mathrm{h}^{*}\left(\mathrm{~W} / \mathrm{m}^{2} \mathrm{~K}\right)\right.$ to correct the heat transfer process of a wet surface:

$$
h^{*}=h\left(1+e \lambda / C_{p a}\right)
$$

Where $\mathrm{h}\left(\mathrm{W} / \mathrm{m}^{2}{ }^{\circ} \mathrm{C}\right)$ is the heat transfer coefficient and $\mathrm{e}$ is constant, given by:

$$
e=\left(\omega_{\max }-\omega_{\min }\right) /\left(T_{\max }-T_{\min }\right)
$$

Here $\mathrm{T}_{\max }, \mathrm{T}_{\min }$ are the maximum and minimum temperatures at the liquid-gas interface. $\mathrm{T}_{\text {max }}$ is the higher one of the temperatures of gas flow and water flow. $\mathrm{T}_{\min }$, is the wet bulb temperature of the air. $\omega_{\max }$ and $\omega_{\min }$ are the maximum and minimum humidity ratios corresponding to $\mathrm{T}_{\max }$ and $\mathrm{T}_{\min \text {. }}$.

\subsection{Dehumidifier modeling}

An energy balance between the cooling water and the air/condensing vapor stream is made the energy balance is based on two following thermal equations [6]:

$$
\begin{gathered}
\dot{m}_{c w} C_{p c w}\left(T_{c w o}-T_{c w i}\right)=\dot{m}_{a}\left(H_{o}-H_{i}\right) \\
\dot{m}_{c w} C_{p c w}\left(T_{c w o}-T_{c w i}\right)=U_{c} A_{c} L M T D_{c}
\end{gathered}
$$

where $\mathrm{m}_{\mathrm{cw}}$, and $\mathrm{m}_{\mathrm{a}}(\mathrm{kg} / \mathrm{sec})$ are the mass flow rate of cooling water and incoming air. $\mathrm{T}_{\mathrm{cwo}}$ and $\mathrm{T}_{\mathrm{cwi}}(\mathrm{K})$ are the temperature of cooling water at inlet and outlet. $\mathrm{H}_{\mathrm{i}}$ and $\mathrm{H}_{\mathrm{o}}(\mathrm{Kj} / \mathrm{kg})$ are the enthalpy of air at inlet and outlet. In Eq. (30) the logarithmic mean temperature difference and the overall heat transfer coefficient are given by the following relations [6]:

$$
\begin{aligned}
& \text { LMTD }_{c}=\frac{\left(T_{a c}-T_{c w o}\right)-\left(T_{a c}-T_{c w i}\right)}{\ln \left(\frac{\left(T_{a c}-T_{c w o}\right)}{\left(T_{a c}-T_{c w i}\right)}\right)} \\
& \frac{1}{U_{c}}=\frac{1}{h_{c i}} \frac{r_{c o}}{r_{c i}}+R f_{c}+\frac{r_{c o} \ln \left(\frac{r_{c o}}{r_{c i}}\right)}{k_{c}}+\frac{1}{h_{c o}}
\end{aligned}
$$

The production of distilled water $\left(\mathrm{m}_{\mathrm{d}}\right)$ is given by the following equation 
$m_{d}=m_{a}\left(\omega_{o}-\omega_{i}\right)$

Where $\omega_{o}$, and $\omega_{i}$ are the absolute humidity $(\mathrm{kg}$ $\mathrm{H}_{2} \mathrm{O} / \mathrm{kg}$ dry air) of air at the inlet and outlet from the condenser.

\subsection{V-groove solar air collector}

A V- shaped flat plate solar air collector is designed, Fig. 4. The calculation of the solar air collector are made with the following assumptions: (i) performance is steady state; (ii) There is no absorption of solar energy by a cover in so far, (iii) The radiation coefficient between the two air duct surfaces is found by assuming a mean radiant temperature equal to the mean fluid temperature. (iv) Loss through front and back are of the same temperature .The energy balances for the absorber plate, back insulation and working fluid of the collector are given by the following, [22]:

In the single pass v-groove absorber:

For the cover:

$\mathrm{U}_{\mathrm{t}}\left(\mathrm{T}_{\mathrm{g}}-\mathrm{T}_{\mathrm{a}}\right)=\mathrm{h}_{1}\left(\mathrm{~T}_{\mathrm{p}}-\mathrm{T}_{\mathrm{g}}\right)+\mathrm{h}_{\mathrm{r}}\left(\mathrm{T}_{\mathrm{p}}-\mathrm{T}_{\mathrm{g}}\right)$

V-groove absorber:

$\tau_{\mathrm{g}} \alpha_{\mathrm{p}} \mathrm{G}_{\mathrm{t}}=\mathrm{h}_{1}\left(\mathrm{~T}_{\mathrm{p}}-\mathrm{T}_{\mathrm{g}}\right)+\mathrm{h}_{\mathrm{r}}\left(\mathrm{T}_{\mathrm{p}}-\mathrm{T}_{\mathrm{g}}\right)+\mathrm{h}_{2}\left(\mathrm{~T}_{\mathrm{p}}-\mathrm{T}_{\mathrm{f}}\right)$

Fluid medium:

$\mathrm{h}_{2}\left(\mathrm{~T}_{\mathrm{p}}-\mathrm{T}_{\mathrm{f}}\right)+\mathrm{U}_{\mathrm{b}}\left(\mathrm{T}_{\mathrm{a}}-\mathrm{T}_{\mathrm{f}}\right)=\left(\frac{\dot{m} C_{\text {air }}}{W}\right)\left(\frac{d T_{\text {air }}}{d x}\right)$

solving equations (5), (6) with (34), (35) and (36), the air, absorber plate temperature and heat transfer coefficient were obtained.

The pressure drop through the channel in the air heater has been computed using the following expression [22]:

$$
\Delta P=\left[f_{o}+y \frac{D}{L}\right]\left(\frac{m_{\text {air }}^{2}}{\rho}\right)\left(\frac{L}{D}\right)^{3}
$$

for laminar flow $(\operatorname{Re}<2550)$

$f_{o}=24 / \operatorname{Re}, \mathrm{y}=0.9$

for transitional flow $\left(2550<\operatorname{Re}<10^{4}\right)$

$f_{o}=0.0094, \mathrm{y}=2.92 \mathrm{Re}^{0.15}$

for turbulent flow $\left(10^{4}<\operatorname{Re}<10^{5}\right)$

$f_{o}=0.059 \mathrm{Re}^{0.2}, \mathrm{y}=0.73$

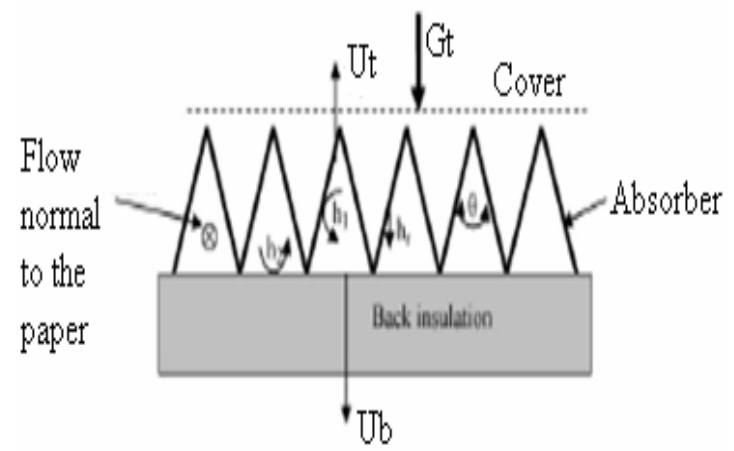

Fig.4 V-Groove air collector

\section{THE SOLUTION PROCEDURE}

The procedure is as follows:

1. The input the known data, such as the mass flow rates of air, feed seawater, cooling water, inlet temperature and humidity of the air are given.

2. The air and water temperature were obtained.

3. The fresh water from the humidifier was collected.

\section{RESULTS AND DISCUSSION}

Fig.5 shows the variations of solar intensity along one day of operation in summer season. The Figure shows that, there is a good agreement between the theoretical model and the measured data. Fig.6 shows the variations of solar intensity along the three days in June, July and August.

Figure 7 shows the characteristic efficiency and operating temperatures of the unit for different collector feed water .Efficiency curve is based on gross collector area and is determined using the outdoor conditions. The thermal efficiency is a function of the outdoor temperature, solar radiation, and the temperature of the fluid at the inlet.

Fig. 8.The figure shows, a comparison between the theoretical and measured accumulative productivity. It can be seen from the curve that, there is as good agreement between the theoretical and experimental results. The accumulative productivity on this day is about $10 \mathrm{~kg} / \mathrm{day} / \mathrm{m}^{2}$.In the real outdoor operation, a delay time was noticed between the start of the run time and the starting of fresh water production, as most of the energy received in early hours is used as sensible heat to warm up the test rig metal pants and the fluid flow.

Figures (9) and (10) show the measured values of the accumulative productivity at different days. It can be seen from the curve that, the average accumulative productivity of the system in winter (November, December and January) is ranged between 2 to $3.5 \mathrm{~kg} / \mathrm{m}^{2}$.day and the average summer productivity is ranged between 7.26 to $11 \mathrm{~kg} /$ $\mathrm{m}^{2}$.day( in June and August ). 
The effect of testing parameters in three operating days such as, feed water, air and cooling water flow rates are presented in Figures (11) and (12).

It seems from Fig. (13) That, for the same weather conditions (solar intensity, ambient temperature and wind speed), the system productivity of the unit increases with increasing the air flow rate in three excessive days. This is due to the fact that increasing the air flow rate leads to an increase in the mass and heat transfer coefficients in the humidifier and hence entrained water vapor, which is lead to an increase in the system productivity.

The effect of cooling water flow rate on the productivity is illustrated in Fig. (14). It is clear from the curve that, Increasing the cooling water flow rate in the dehumidifier leads to a decrease in the surface temperature of the air cooler and this will lead to an increase in the condensation rate and hence the system productivity

Figure (15) shows the effect of solar intensity on the water productivity on 22 July 2009. The measured values of the average solar radiation and ambient temperature during 22 July 2009, in Port Said-Egypt are given in Figure (16). The Average relative humidity of the ambient air is $50-60 \%$ and the wind speed ranges between 1 and $3 \mathrm{~m} / \mathrm{s}$.

Figure (17) represents the air relative humidity at the inlet and outlet of the humidifier for the indicated climatic conditions. One can notice that, the relative humidity at the exit of the humidifier is close to the value of $95 \%$. Due to the air heater device output, the outlet relative humidity appears constant; independent on the inlet one. This result means that, the air leaving the humidifier is practically saturated.

Figure 18 shows the effect of the inlet temperature and relative humidity of air on the unit water productivity. The results agree with the common knowledge in literature, that the higher inlet temperature and humidity are beneficial for producing more fresh water. The solar water productivity of the unit increases with the inlet temperature and relative humidity. It is clear from the curve also that the humidity has a strong influence on the system performance especially at the higher inlet temperature of air.

Two different packing materials have been used in the test rig. The total surface area of the packing has been kept constant. However, the wetted area differs from one type to anther depending on the nature of each material. Figure 19 shows the variation of the daytime accumulative productivity for the two packing materials under same operating conditions.
Figure (20) shows the effect of different honeycomb packing material in the humidifier on the productivity.

Fig.21 shows the effect of the humidifier inlet water temperature on the unit productivity. It can be noticed that, the productivity decreases with increasing the water flow rate. This can be explained by the fact that increasing the water flow rate leads to a decrease of the enthalpy of air, hence, the he ability to extract vapor from the air is decreased.

The effect of inlet air temperature on the productivity is shown in Fig. 22. It can be seen from the curve that, the ability of air to carry the water vapor increases with the increase of the inlet air temperature.

Fig. 23 shows the effect of solar intensity on the humidifier inlet temperature. It can be seen from the curve that, the increase of solar intensity increases the unit air temperature and hence increases the water productivity.

Figure 24 shows the effect different of inlet water temperature on the productivity. It can be seen from the curve that, the productivity increases with decrease of inlet cooling water temperature

The effect of the solar collector tilt angle variation on the solar desalination unit is theoretically investigated and presented in Fig. 25. It is evident that, the productivity increases with the increase of tilt angle slope in winter. However Fig. 26 show that, the productivity increases with the decrease of tilt angle slope in summer.

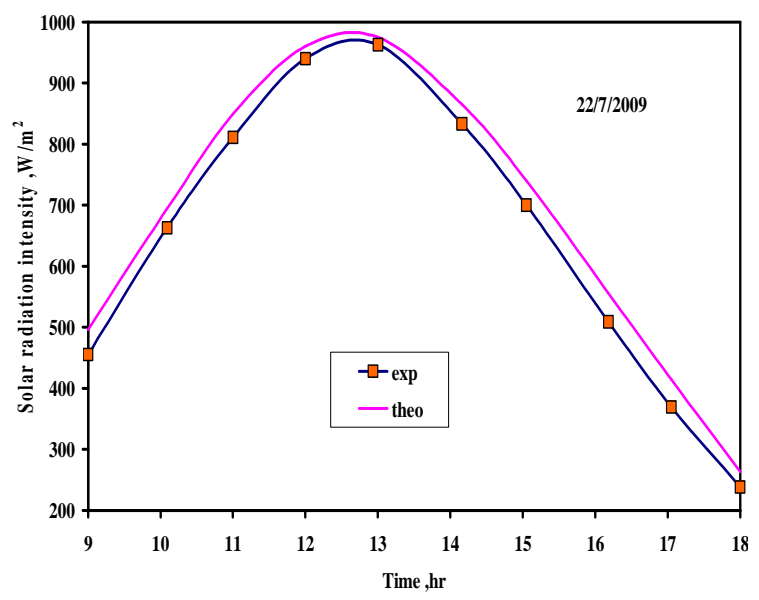

Fig. 5 The hourly variation of solar radiation during 22/7/2009 
M.Abd ElKader, Aref., A., Gamal H. Moustafa, Yasser ElHenawy, " A Theoretical and Experimental ... "

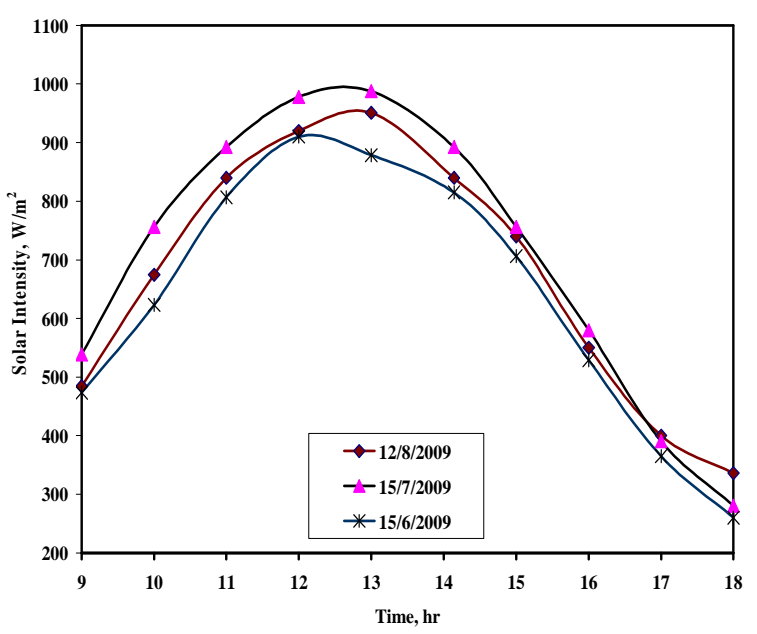

Fig. 6 The hourly variation of solar radiation along three operating days on summer

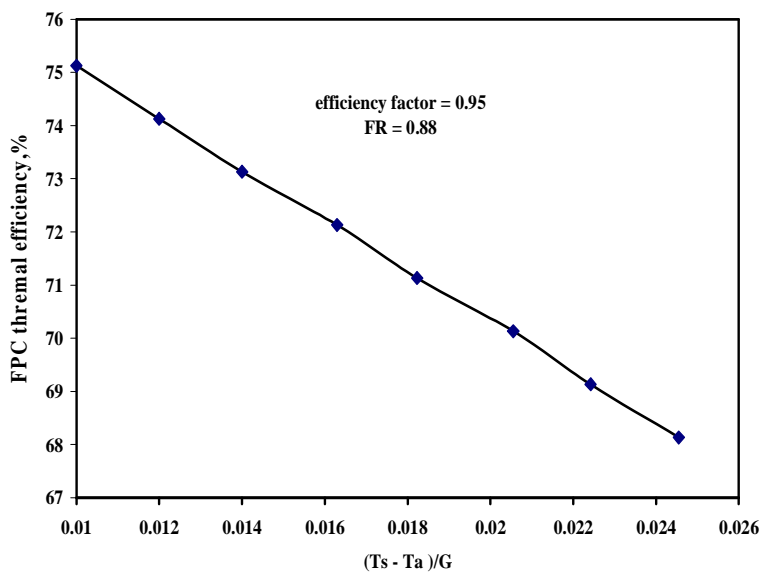

Fig.7 The instantaneous Efficiency of solar water collector

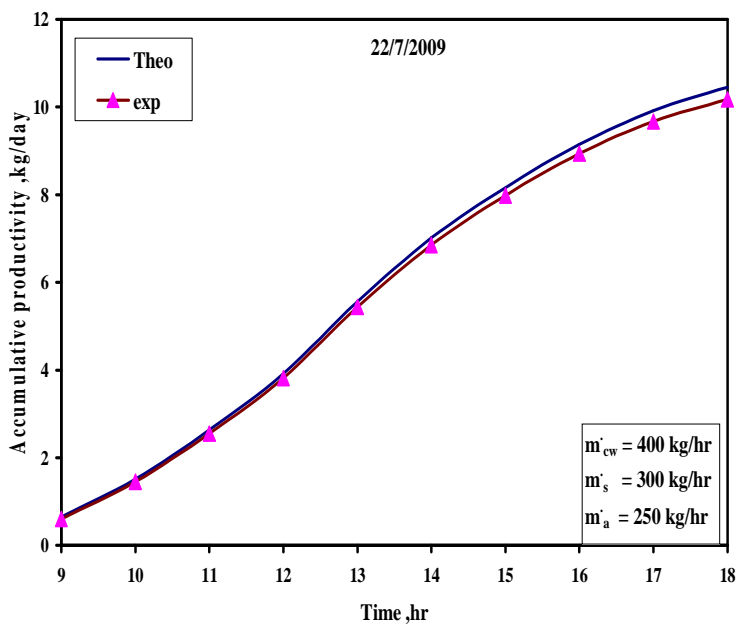

Fig. 8 Hourly accumulative productivity 22/7/2009

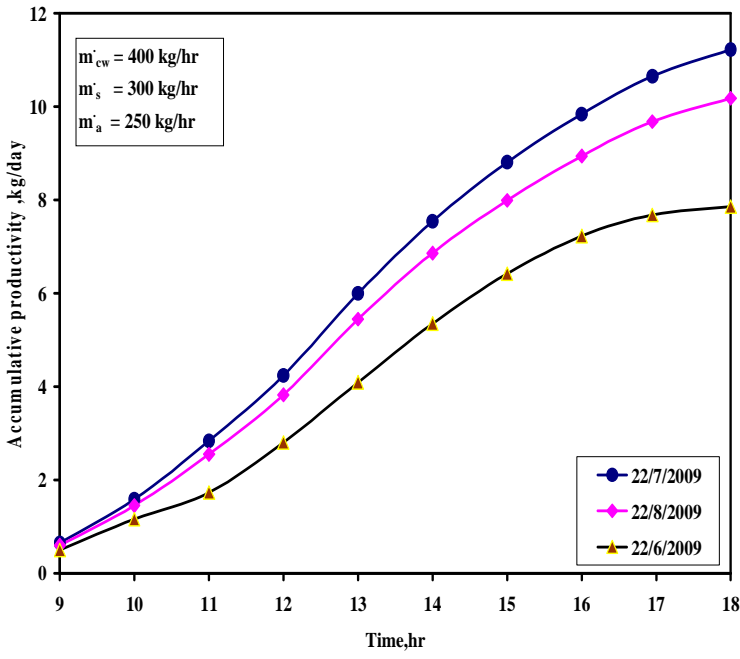

Fig. 9 The variations of accumulative productivity during June, July and August

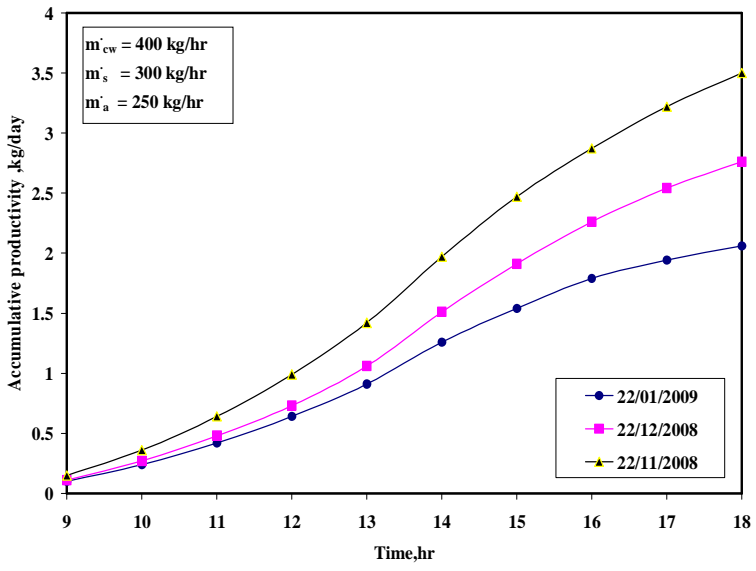

Fig.10 The variations of accumulative productivity during November, December and January

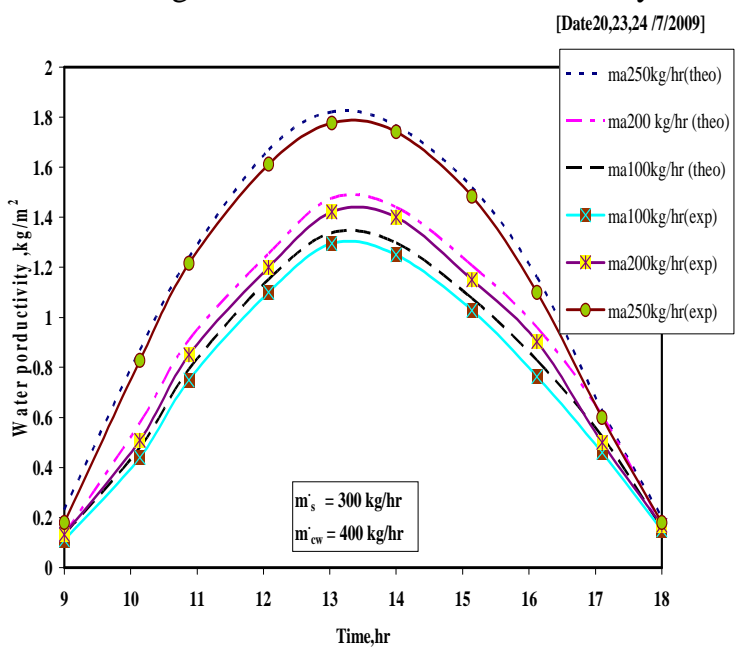

Fig.11 Effect of feed water mass flow rate on hourly system productivity 
M.Abd ElKader, Aref., A., Gamal H. Moustafa, Yasser ElHenawy, " A Theoretical and Experimental ... "

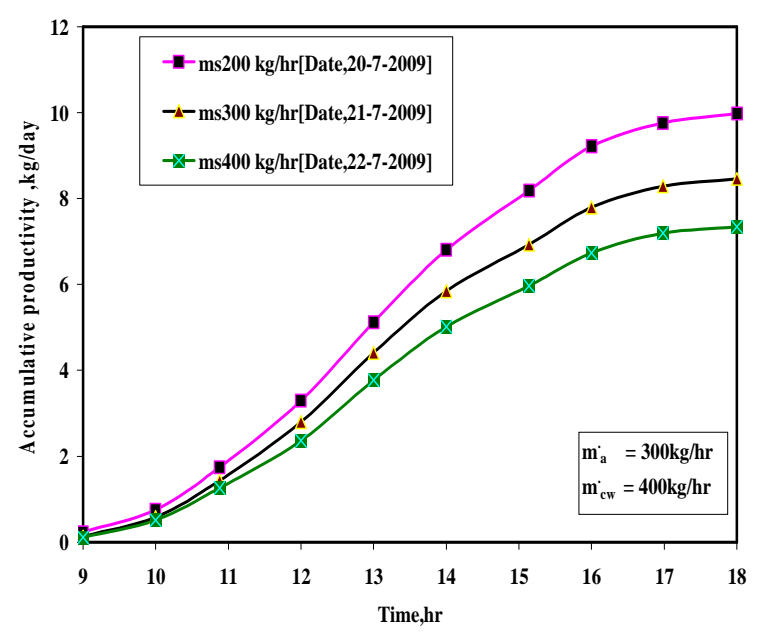

Fig. 12 Effect of feed water mass flow rate on accumulative productivity

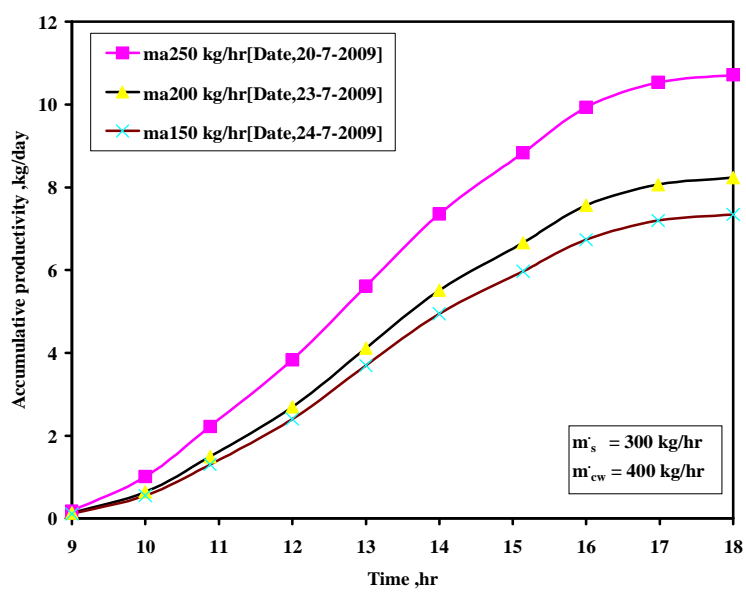

Fig.13 Effect of air mass flow rate on accumulative productivity

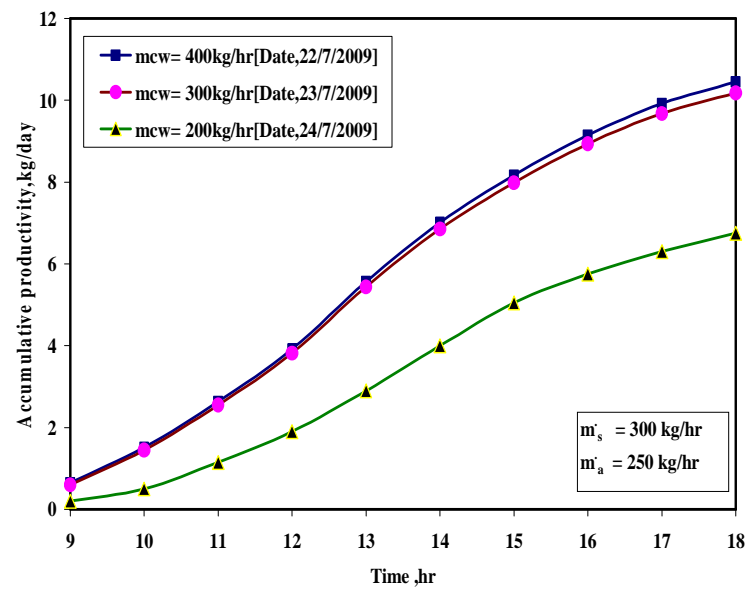

Fig.14 Effect of dehumidifier cooling water flow rate on accumulative productivity

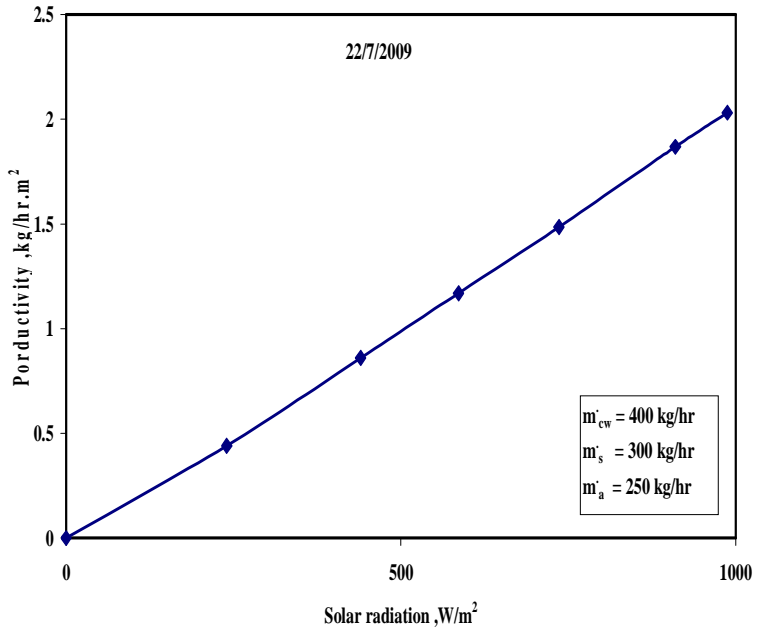

Fig.15 Effect of solar radiation intensity on the productivity

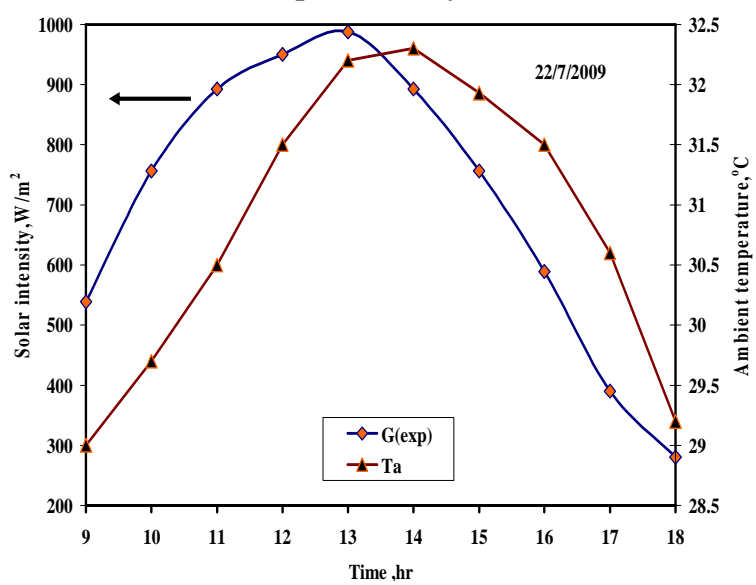

Fig.16 Variation of solar radiation on a horizontal surface and ambient temperature during 22/7/2009

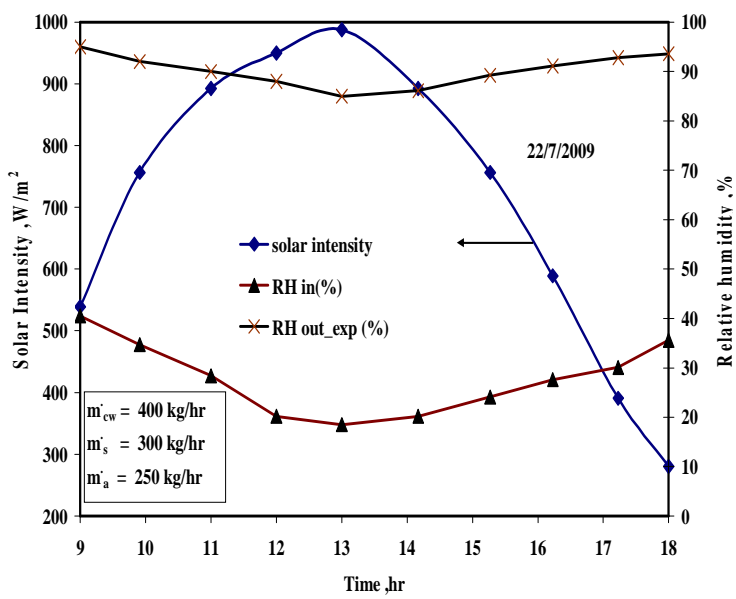

Fig.17 hourly variation of relative humidity of air at the inlet and outlet of the humidifier 
M.Abd ElKader, Aref., A., Gamal H. Moustafa, Yasser ElHenawy, " A Theoretical and Experimental ... "

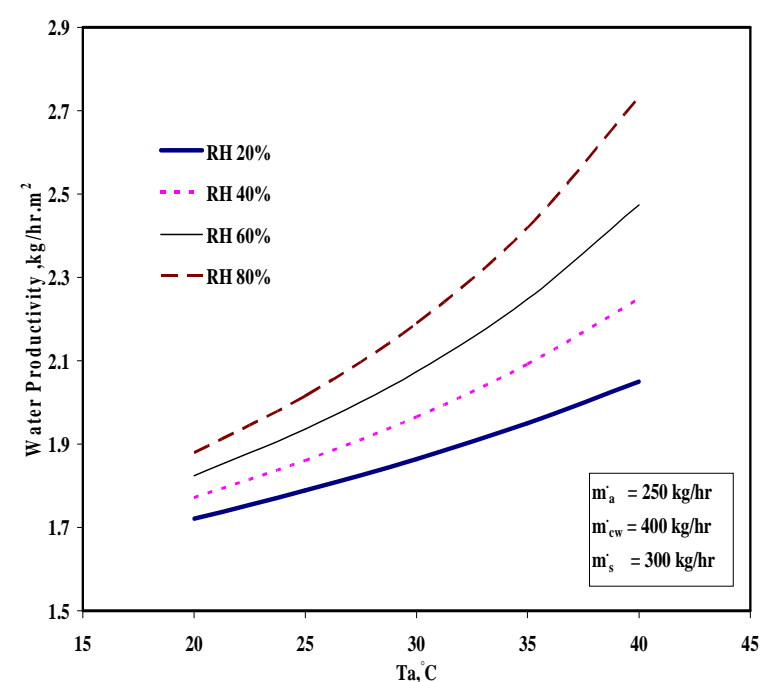

Fig.18 Effect of relative humidity on water productivity at different air temperature

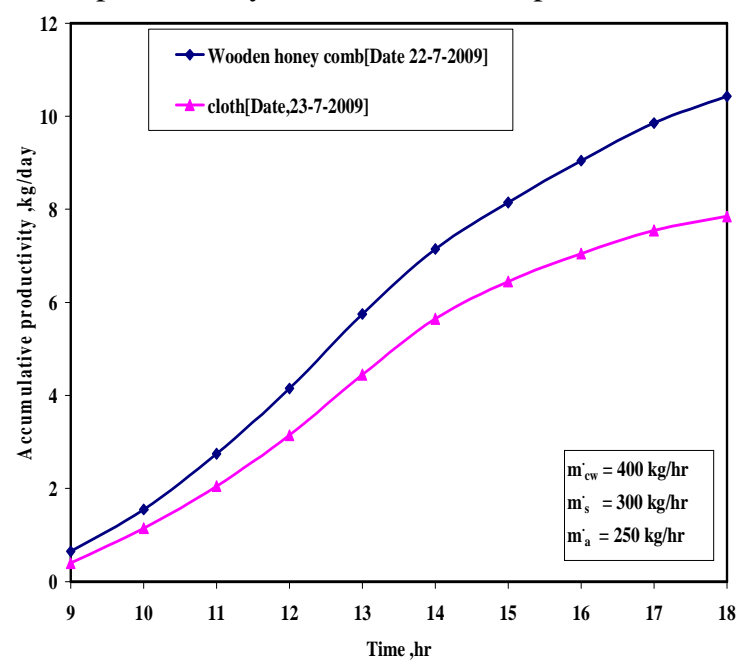

Fig.19 Effect of two different packing materials on hourly accumulative productivity

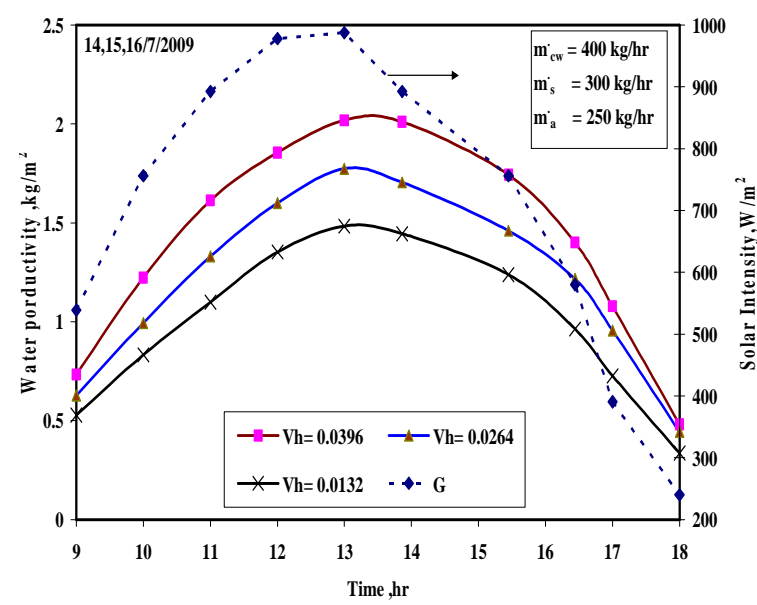

Fig.20 Effect of different volume of honey- comb packing materials on the productivity

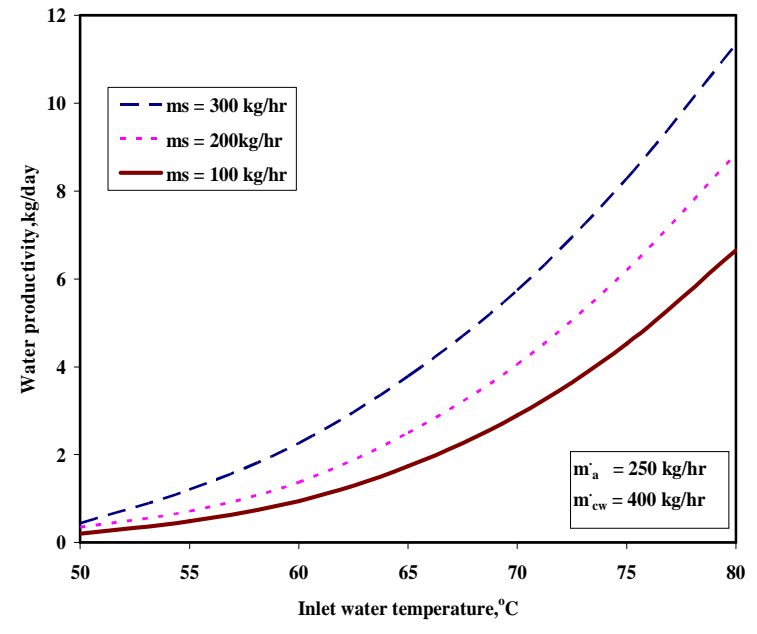

Fig.21 Effect of humidifier inlet water temperature on the unit productivity

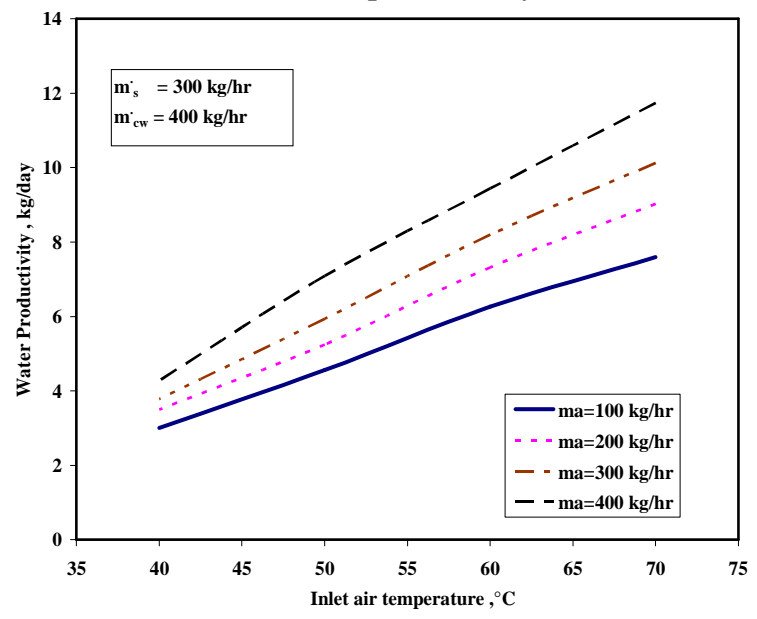

Fig.22 Effect of humidifier inlet air temperature on the unit productivity

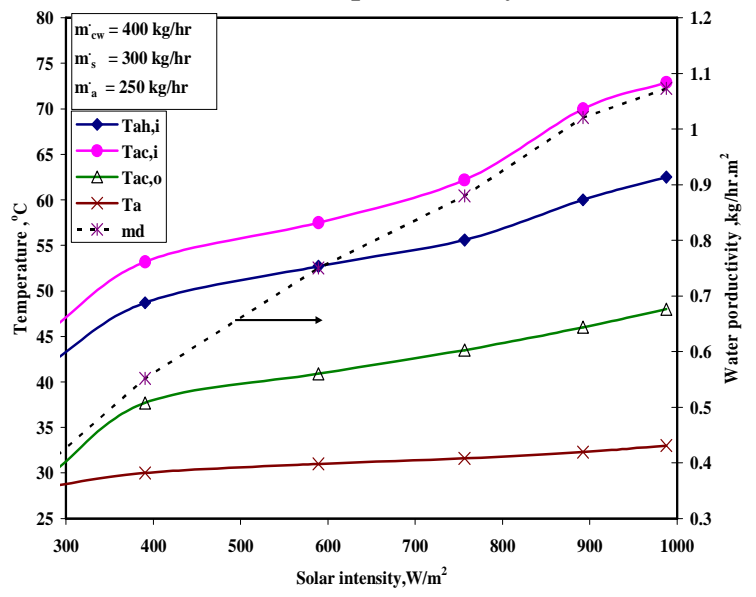

Fig.23 Effect of solar intensity on humidifier inlet air temperature and water productivity 


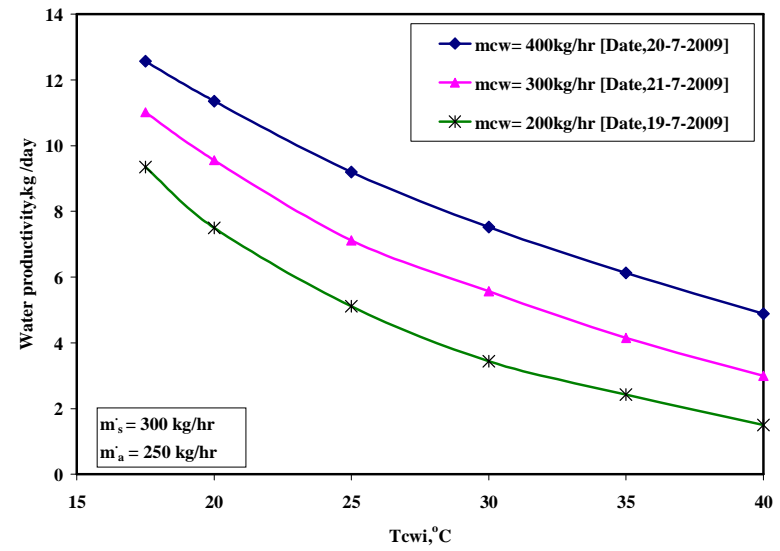

Fig. 24 Effect of different temperature of cooling inlet seawater on the water productivity

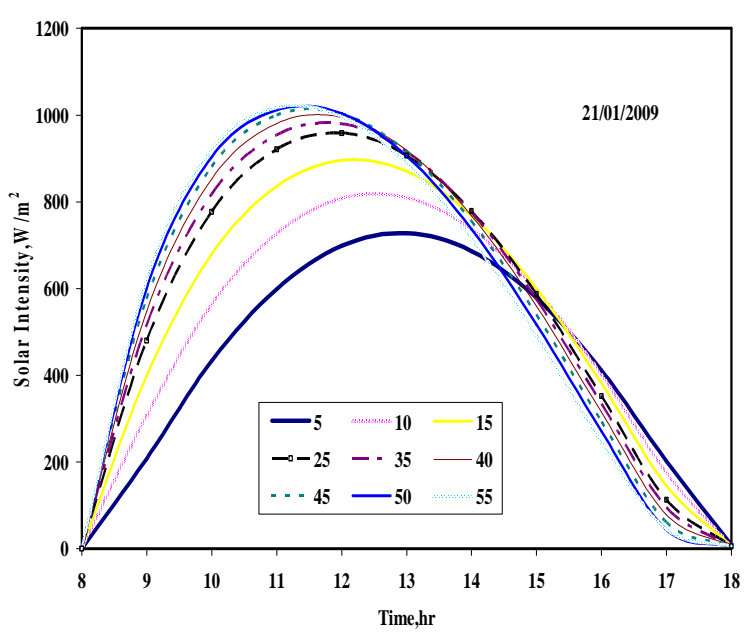

Fig. 25 Effect of the collector tilt angle on the solar radiation unit in winter

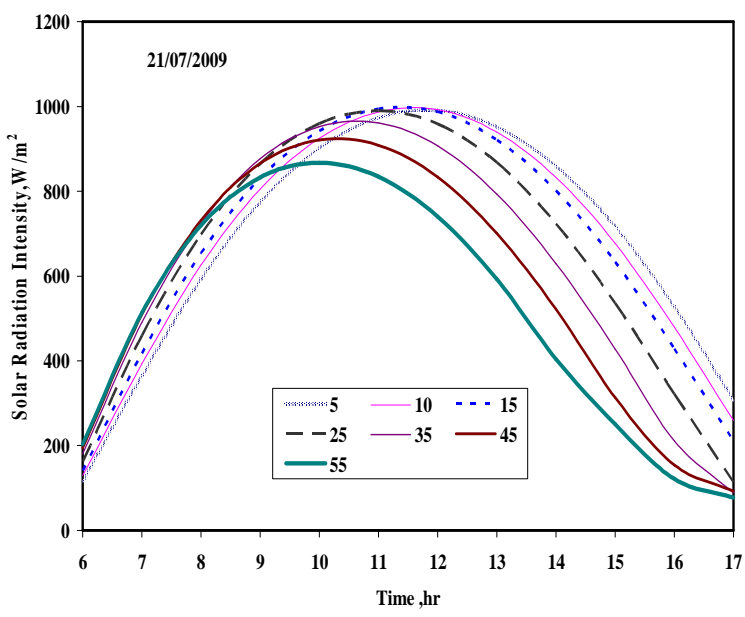

Fig.26 Effect of the collector tilt angle on the solar radiation unit in summer

\section{CONCLUSIONS}

A humidification - dehumidification (HD) system has been designed, installed and outdoor tested in the faculty of Engineering, Suez Canal University, Port Said, Egypt. The system consists of an insulated desalination chamber coupled with a solar Collector. The desalination chamber divided into evaporator tower and dehumidifier tower. A parametric analysis was conducted based on numerical simulation in order to optimize the system performance. The system was found to be suitable to provide drinking water for population or remote arid areas. It can be seen from the above test results that:

1. A mathematical model is written for the all system components(collectors, humidifier, dehumidifier) to predict the system productivity under different and wide range of operating conditions.

2. It is found that the accumulative productivity increases with the increase of inlet air temperature and relative humidity.

3. Increasing the seawater flow rate leads to decrease in water productivity to a certain value depending on the collector efficiency.

4. The water productivity of the unit increases with the increase of packing material volume.

5. The optimum tilt angle which gives maximum solar radiation is found between $35: 45^{\circ}$ in winter and $15: 20^{\circ}$ in the summer.

6. The results of the proposed mathematical model are in good agreement with those of the experimental model of the system.

7. The system daily productivity in summer is about 7.26 to $11 \mathrm{~kg} / \mathrm{m}^{2}$ day, and about 2 to 3.5 $\mathrm{kg} / \mathrm{m}^{2}$ day in winter.

Symbols

d Mean wall spacing, $\mathrm{m}$

K Thermal conductivity (W/m K)

$\mathrm{Ps}$ Saturated water vapor pressure, $\mathrm{Pa}$

$\mathrm{Pv}$ Water vapor pressure of the air, $\mathrm{Pa}$

Vh Volume of packing materials in the humidifier, $\mathrm{m} 3$

$\mathrm{u}, \mathrm{v} \quad$ Velocity, $\mathrm{m} / \mathrm{s}$

h Heat transfer coefficient, W/(m2.s)

r Radius , $m$

RH Relative humidity

Rf Fouling resistance, $\mathrm{m} 2 \mathrm{oC} / \mathrm{kW}$

Greek

$\delta \quad$ Thickness (m)

$\alpha \quad$ Thermal diffusitivity, $\mathrm{m} 2 / \mathrm{s}$

$\gamma \quad$ Kinematic viscosity, $\mathrm{m} 2 / \mathrm{s}$

$\lambda$ Latent heat of water, $\mathrm{kJ} / \mathrm{kg}$ 
M.Abd ElKader, Aref., A., Gamal H. Moustafa, Yasser ElHenawy, " A Theoretical and Experimental ... "

$\mu \quad$ Dynamic viscosity, $\mathrm{N} / \mathrm{m} 2 . \mathrm{s}$

$\rho \quad$ Density, $\mathrm{kg} / \mathrm{m} 3$

$\varepsilon \quad$ Coefficient of evaporation

$v \quad \mathrm{~V}$-groove angle of solar air heater, degree Subscripts
b Bottom, box
c Dehumidifier
cw cooling water
i Inlet state, insulation
s Saline water
si Side
p Plate
n Liquids interface
o Outlet
V Water vapor

\section{REFERENCES}

[1] Abdel-Monem M, Abdel-Salam M, and Abdelwahed, "Theoretical and Experimental Studies of Humidification-Dehumidification Desalination System", Ph.D. Thesis, Department of Mechanical Engineering, Faculty of Engineering, Cairo Univ., Egypt, 1988.

[2] Al-Hallaj S., and Farid, M., "Solar Desalination with a Humidification-Dehumidification Cycle: Performance Unit", Desalination 120(1998) 273-280.

[3] Darwish M.A.," Experimental and Theoretical Study of Humidification - Dehumidification Desalting System", Desalination 94, 11-24.

[4] Dai, Y.J., Wang, R.Z., and Zhang, H.F., "Parametric Analysis to Improve the Performance of a Solar Desalination Unit with Humidification and Dehumidification", Desalination 142 (2002) 107-118.

[5] Eames, I.W., Marr, N.J., and Sabir, H., Int. J. Heat and Mass Transfer., 40 (1997) 2963-2973.

[6] Ettouney, H. "Design and Analysis of Humidification Dehumidification Desalination Process", Desalination 183 (2005) 341-352

[7] Fath H.E. "Desalination Technology- The Role of Egypt in Region", IWT C 2000, Alexandria, Egypt.

[8] Fath H.E., "Solar Desalination Promising Alternative for Fresh Water Production with Free Energy Simple Technology and Clean Environmental", Desalination 1998 (116) 45-56.

[9] Fath H.S., and Ghazy A., "Solar Desalination Using Humidification-Dehumidification", IWT C, Alexandria, Egypt 2000.
[10] Gao, P. Zhang, L., and Zhang, H., "Performance Analysis of a New Type Desalination Unit of Heat Pump with Humidification and Dehumidification", Desalination 202 (2008) 531-537.

[11] Garg, H.P., Adhikari, R.S., and Kumar, R., "Experimental Design and Computer Simulation of Multi-Effect Humidification (MEH)-Dehumidification Solar Distillation", Desalination 153 (2002) 81-86.

[12] John A., William, D. and Beckman, A., "Solar Engineering of thermal processes", New York, USA: John Wiley; 1980.

[13] Kettleborough, C.F., and C.S. Hsieh, C.S., J. Heat Transfer, 105 (1983) 366-375.

[14] MacLaine, I.L., Cross and Banks, P.J., J. Heat Transfer, 103 (1981) 579-585.

[15] Marmouch, H., Orfi, J., and Ben Nasrallah, S., "Effect of a Cooling Tower on a Desalination System", Desalination 238 (2007) 281-289.

[16] Moustafa M., Elsayed, Ibrahim S. Taha, and Jaffer A.Sabbagh., "Design of Solar Thermal Systems", Jeddah ,Saudi Arabia ,1994.

[17] Abdelkader M.,Nafey A.S., Abdelmotalip A., and Mabrouk A. A., "Parameters Affecting Solar Still Productivity", Energy Conversion and Management, 411(2000) 797-809.

[18] Abdelkader M.,Nafey A.S, Abdelmotalip A., and Mabrouk A.A., "Solar Still Productivity Enhancement", Energy Conversion and Management 42 (2001) 1401-1408.

[19] Abdelkader M.,Nafey A.S, Abdelmotalip A., and Mabrouk A.A., "Enhancement of Solar Still Productivity Using Floating Perforated Black Plate", Energy Conversion and Management 43 (2001) 1401-1408.

[20] Nafey, A.S., Mohamad, M.A., El-Helaby, S.O., and Sharaf, M.A., "Theoretical and Experimental Study of a Small Unit for Solar Desalination Using Flashing Process", Energy Conversion and Management 48 (2007) 528538.

[21] Yamali, C., and Solmus, I., "Theoretical Investigation of a Humidification Dehumidification Desalination System Configured by a Double Pass Flat Plate Solar Air Heater", Desalination 205 (2007) 163-177.

[22] Tchinda R."A review of the mathematical models for predicting solar air heaters systems" Renewable and sustainable energy reviews 640 (2009)1-26. 